\title{
A perspectiva decolonial e a geografia política na graduação brasileira atual
}

\author{
Daniel Abreu de Azevedo \\ Colégio Pedro II
}

\section{revista}

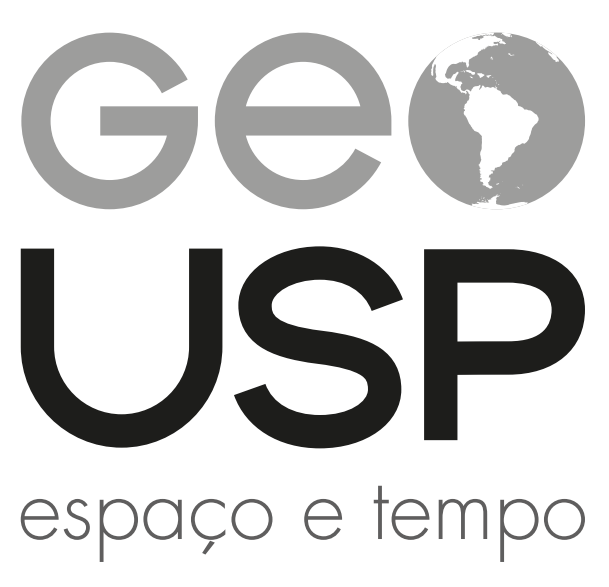

Volume $23 \cdot n^{\circ} 3(2019)$

ISSN 2179-0892 p. $564-581$

Como citar este artigo:

AZEVEDO, D. A. A perspectiva decolonial e a geografia política na graduação brasileira atual. Geousp - Espaço e Tempo (Online), v. 23, n. 3, p. 564-581, dez. 2019, ISSN 2179-0892.

Disponível em: https://www.revistas.usp.br/geousp/article/view/158726. doi: https://doi.org/10.11606/issn.2179-0892.geousp.2019.158726.

\section{(c) $($ (1) (8)}

Este artigo está licenciado sob a Creative Commons Attribution 4.0 Licence 


\title{
A perspectiva decolonial e a geografia política na graduação brasileira atual
}

\section{Resumo}

Apesar de ter raízes literárias e empíricas que remontam à primeira metade do século XX, foi a partir de 1990 que a teoria decolonial começou a ganhar corpo e influenciar a agenda de diferentes ciências humanas. É dentro da Geografia, da Ciência Política, da Sociologia latino-americana que vemos essa perspectiva florescer mais, especialmente nos países hispânicos. O objetivo do artigo é avaliar a importância da agenda decolonial no ensino de Geografia Política (GP) em importantes cursos de graduação do país, a partir de suas ementas e programas. Depois de apreciar a importância da perspectiva decolonial na agenda da Geografia Política, o artigo conclui que, nos oito cursos de graduação analisados (UFRJ, UFF, UFRGS, UFMG, Unicamp, Unesp-PP e UFC), persiste o vínculo histórico com a produção acadêmica europeia (especialmente a francesa) e estadunidense, afastando a GP brasileira da produção de seus vizinhos regionais.

Palavras-chave: Decolonialidade. Teoria decolonial. Geografia política. Cursos de graduação. Brasil.

\section{The decolonial perspective and the Political Geography of the current Brazilian undergraduation}

\begin{abstract}
Despite having literary and empirical roots dating back to the first half of the twentieth century, it was from 1990 that decolonial theory began and influence the agenda of different human sciences. It is within Geography, Political Science, and Latin American Sociology that we see this perspective flourish with greater emphasis, especially in the Hispanic countries. The objective of our article is to evaluate the importance of the decolonial agenda in Political Geography's classes (GP) in undergraduate courses of the country. After an appreciation of the importance of the decolonial perspective for Political Geography agenda, our
\end{abstract}


article concludes that in the eight courses analyzed (UFRJ, UFF, UFRGS, UFMG, Unicamp, Unesp-PP and UFC) the historical link with European academic productions (especially France) and the U.S., distancing Brazilian Political Geography from the productions of its regional neighbors.

Keywords: Decoloniality. Decolonial theory. Political Geography. Undergraduate courses. Brazil.

\section{La perspectiva decolonial y la Geografía Política en universidades brasileñas}

\section{Resumen}

A pesar de tener raíces literarias y empíricas desde la primera mitad del siglo XX, fue a partir de 1990 que la teoría de la descolonización empezó a ganar cuerpo e influir en la agenda de diferentes ciencias humanas. Es dentro de la Geografía, de la Ciencia Política, de la Sociología latinoamericana que vemos esa perspectiva florecer con mayor énfasis, especialmente en los países hispanos. El objetivo del artículo es evaluar la importancia de la agenda decolonial en la enseñanza de Geografía Política (GP) en importantes cursos de licenciatura y bachilleratos del país, a partir de sus programas. El artículo concluye que en los ocho cursos analizados (UFRJ, UFF, UFRGS, UFMG, Unicamp, Unesp-PP y UFC) es persistente el vínculo histórico con las producciones académicas europeas (especialmente francesa) y estadounidense, alejando a la GP brasileña de las producciones de sus vecinos regionales.

Palabras clave: Decolonialidad. Teoría decolonial. Geografía política. Cursos de graduación. Brasil. 


\section{Introdução}

A virada decolonial na América Latina nos últimos dez anos é um marco dentro de diferentes áreas de conhecimento, desde os cursos de Administração (Abdalla; Faria, 2015) e Contabilidade (Sauerbronn; Ayres; Lourenço, 2017) aos de História (Oliveira, 2018), Antropologia (Castro, E., 2002, 2015), Ciência Política (Ballestrin, 2013) e até na própria Geografia (Rocha, 2018; Loback; Bezerra, 2018), configurando-se como um importante paradigma-outro, como a denominam seus principais autores.

Os rebatimentos do paradigma decolonial se dão em diferentes campos de conhecimento, enriquecendo e trazendo novas perspectivas de análise. Defendemos que o debate decolonial pode expandir e enriquecer a agenda da Geografia Política, a partir do momento em que a ordem global baseada no sistema de Estados-nações num sistema de mercado é colocada entre parênteses, não como mais um modo de negá-la e/ou de construir uma alternativa que também se pretenda universal, mas na medida em que se afirma a necessidade de pensar múltiplos mundos possíveis em coexistência. Assim, o objetivo deste artigo é analisar se e como a Geografia Política em importantes cursos de graduação no Brasil incorporou a discussão dessa virada decolonial, a partir de suas ementas e programas. Para tanto, optamos por enfocar a perspectiva decolonial sobre a figura do Estado-nação, pois acreditamos que é em torno desse tema que a maior parte da literatura tradicional e contemporânea da Geografia Política brasileira continua estruturada.

Desde a fundação da Geografia Política a partir da tradição ratzeliana, o Estado sempre se configurou como um elemento central de análise. Depois das suas supostas consequências práticas como suporte para o imperialismo e o nazifascismo - o que Iná Elias de Castro (2005) chama de "o pecado original" que desencadeou um abandono da disciplina - a Geografia Política se dedicou a outros temas, mas ainda assim o Estado e suas instituições continuaram como um dos principais eixos analíticos. Entretanto, como revelamos ao longo deste artigo, a Geografia Política brasileira ensinada nos cursos selecionados de graduação não vê a teoria decolonial como uma importante perspectiva para interpretar o Estado e/ou fenômenos alheios a ele. Ao revelar o completo afastamento do debate decolonial, nosso artigo sugere que há uma perda importante em riqueza conceitual e empírica dos alunos de graduação que são privados de conhecer durante sua formação.

Optamos aqui pela perspectiva decolonial desenvolvida em países vizinhos, pois o objetivo central é demonstrar que a formação da Geografia Política brasileira se assemelha à própria formação espacial do país, isto é, estamos ainda muito vinculados à produção europeia, especialmente a francesa, e afastados da América Latina. Em tese, os debates conduzidos por autores hispânicos teriam mais capilaridade em temas tradicionais da Geografia Política brasileira, por nossas relações históricas e culturais, além da óbvia proximidade geográfica. Por outro lado, isso

1 Isso não significa que não existam outras e interessantes contribuições da virada decolonial para a Geografia Política. O esforço de reconstrução teórica e histórica da ideia de poder e dominação alicerçada na ideia de raça e, com isso, uma ampliação e reformulação a teoria do sistema-mundo moderno, agora visto como moderno/colonial é, sem dúvida, um campo fértil para a Geografia Política, visto que a teoria do poder, da dominação e do sistema-mundo é tema no centro discursivo do campo da geografia política, como demonstra a conhecida obra de Colin Flint e Peter Taylor (2011[1989]). A escolha por discutir apenas a ideia de Estado-nação se justifica por sua importância na Geografia Política e pelos limites práticos deste artigo. 
não quer dizer que contribuições importantes, incluindo aquelas produzidas pela primeira geração do pensamento pós-colonial (como a obra de Frantz Fanon comentada adiante), não sejam também interessantes para a Geografia Política brasileira. A opção aqui se dá por uma simples escolha geográfica - a reconhecida falta de pontes entre Brasil e países hispânicos.

Para tanto, o artigo está dividido em três seções, além dessa introdução e das considerações finais: no primeiro, a riqueza conceitual da teoria decolonial será apresentada, apontando caminhos teóricos e empíricos que se abrem para a Geografia Política a partir dessa discussão epistemológica. No segundo, analisaremos as ementas e programas dos cursos de Geografia Política de importantes graduações do país. Por último, refletiremos sobre possíveis razões que ajudam a explicar esse afastamento, antes de concluirmos com sugestões para uma expansão da agenda da Geografia Política brasileira.

\section{O pensamento decolonial: perspectivas enriquecedoras para a Geografia Política brasileira}

Há 64 anos, países africanos e asiáticos se encontraram na conhecida Conferência de Bandung, inseridos num contexto de luta pela descolonização em relação aos países europeus. Além de um momento que marcou os movimentos independentistas, a ideia de desprendimento do comunismo e do capitalismo trazida nesse encontro de nações em 1955 pode ser considerada o marco geopolítico do pensamento decolonial. Três anos antes, Frantz Fanon havia publicado Pele negra, máscaras brancas, que é ainda hoje reconhecido como um pilar literário do movimento decolonial (Mignolo, 2014a), junto com a produção seguinte do mesmo autor Os condenados da terra (1961). Essas sementes germinariam décadas adiante, principalmente nas obras de Anibal Quijano e Walter Mignolo.

Na busca por construir uma autonomia intelectual, ou como o autor dizia uma "racionalidade alternativa" (Rubbo, 2018), Quijano vai descobrir na obra do também peruano Mariátegui e sua crítica ao eurocentrismo dominante no materialismo histórico, ${ }^{2}$ um modo de buscar a especificidade da América Latina, afastando-se de explicações estruturalistas e evolucionistas que dominavam o ambiente acadêmico nas décadas de 1960-70. Assim, é possível afirmar que Quijano é o principal responsável pela construção da ideia de "colonialidade do poder" e, consequentemente, por um verdadeiro "momento de ruptura no campo das ciências humanas e uma nova inspiração" (Segato, 2014, p.12). Sem se esgotar com a colonização e se estendendo para além dos processos de independência, a decolonialidade do poder é o resultado de um padrão de controle, hierarquização e classificação da população mundial que afeta todas as dimensões da existência social (Escobar, 2003; Quijano, 2005; Maldonado-Torres, 2007).

Portanto, o conceito de colonialidade não é sinônimo de colonialismo, visto que esses países já são politicamente independentes há praticamente dois séculos. Os principais autores da corrente decolonial afirmam, entretanto, que a independência não teria significado a quebra da estrutura global de dominação racial, étnica e também epistêmica (Quijano, 1992, 2000, 2005; Mignolo, 2014a; Walsh, 2014; Grosfoguel, 2016) e, consequentemente, seria importante revelar como o pensamento latino-americano ainda é atravessado pela colonialidade do poder.

2 Não cabe aqui discutir a relação entre esses dois autores. Para tanto, ver Rubbo (2018). 
Com a discussão desenvolvida por Quijano, a América hispânica se tornou a região com maior produção acadêmica de perspectiva decolonial, apesar de muitos autores no continente africano e asiático também terem papel fundamental nesse debate (ver, por exemplo, a obra de Guha, 1998).

A perspectiva decolonial sistematizada por autores como Nelson Maldonado-Torres e Quijano buscou uma "descolonização epistemológica", cuja crítica ao evolucionismo unilinear e unidimensional do eurocentrismo seria o norte para construir uma teoria "filosófica, epistemológica, ética e política fundacional sobre a especificidade da América Latina" (Rubbo, 2018, p. 388). Cabe lembrar que o que se denomina pensamento descolonial não se resume à ideia de "giro decolonial" defendida por esses autores. Como afirma Cruz (2017, p. 21), "a nossa história é a história do colonialismo e sua herança, mas também é a história das resistências e lutas dos grupos subalternizados contra essa realidade" e, por isso, é uma verdade histórica que somos marcados por lutas e formulações de pensamentos que buscavam superar a colonialidade. Optar, aqui, por apresentar a perspectiva apresentada na ideia de giro decolonial é uma opção analítico-metodológica que não nega as diferentes vertentes existentes.

Assim, o giro decolonial se estabeleceu contra os pensamentos únicos produzidos por três importantes correntes: a liberal-economicista imperial, o marxismo revolucionário e o cristianismo salvacionista (Walsh, 2014). Por serem igualmente frutos da modernidade, os dois primeiros (e os que nos interessam aqui) compartilhariam, segundo Mignolo (2014b), as mesmas categorias, não mudando a lógica, apesar de ser claro que o marxismo revolucionário teria invertido o conteúdo do primeiro. Por isso, ambas as correntes compartilhariam a visão de uma história única, característica que a perspectiva decolonial se afastaria ao buscar a pluriversalidade em oposição à universalidade. $O$ desprendimento da virada decolonial propõe transformar os termos do debate, não somente o seu conteúdo. Para Chevallier (2009, p. 122) "uma perspectiva epistêmica descolonial exige um cânone de pensamento mais amplo do que o cânone ocidental (incluindo o cânone ocidental de esquerda)". Importante destacar que o pensamento decolonial não se insere na corrente usualmente denominada pós-modernismo. Até mesmo autores da Geografia (ver esse debate em Paulo César Gomes, 1996) já revelaram como o pós-modernismo é irmão do próprio modernismo, numa aparente contradição inerente à própria modernização.

Em suma, a perspectiva decolonial não busca ser mais uma explicação universal no lugar de outras propostas que já existem, mas ela se fundaria na defesa de que é possível e desejável a existência de vários mundos em coexistência. Para isso, é necessário colocar em xeque crenças sociopolíticas há muito enraizadas nas produções acadêmicas. É nesse sentido que caminha Mignolo (2014b) ao defender uma "desobediência epistêmica" para combater o "epistemicídio" (Santos, 2006) promovido pela colonialidade do saber.

\section{O Estado-nação na perspectiva decolonial para a Geografia Política}

Em Key Concepts in Political Geography, Mary Gilmartin (2009) afirmou que a ideia principal de Estado-nação que interessou historicamente à Geografia Política foi sua concepção como a junção entre a soberania territorial e a comunidade formada por populações que se conectam mutuamente a partir de uma história, língua, religião e outras práticas culturais 
comuns. Essa concepção de Estado-nação bebe do movimento filosófico e literário do romantismo do século XIX, "ambiente cultural que favoreceu o surgimento de ideologias nacionalistas a partir da concepção romântica de que a unidade política do Estado é precedida pela unidade linguística, racial e consuetudinária do povo" (Porto-Gonçalves; Quental, 2012, p. 10). Sem dúvida, esse foi o norte de muitos estudos do que se denomina Geografia Política tradicional (Castro, I., 2005; Costa, 2010).

Nas últimas décadas, a Geografia Política foi influenciada por teorias estruturalistas oriundas mais da Economia Política que, a grosso modo, buscavam traçar as ambiguidades e as desigualdades na própria constituição do Estado tal como se apresentava, funcionando como um instrumento da perpetuação de clivagens sociais históricas (Flint; Taylor, 2011[1989]; Harvey, 1993; Corrêa, 1996). Em contrapartida, essas análises, de modo geral, não se livravam da lógica analítica que havia fundado a Geografia Política, isto é, a crença de que o formato social em Estados era um fato dado e que a busca deveria ser pela mudança do conteúdo e não necessariamente de sua forma. ${ }^{3}$ Por essa razão, os geógrafos decoloniais fazem questão de diferenciar o que seria uma Geografia Política Critica de um Geografia Política Decolonial, pois a primeira, ao fim e ao cabo, imaginaria, construiria e organizaria o espaço mundial de acordo com os interesses do emitente e num contexto fundado pela colonialidade do poder (Quijano, 2000; Rocha, 2018). É sobretudo a partir das décadas de 1980-90 que essa cena sofre uma mudança, com a influência, por exemplo, de autoras feministas e de estudos queer. ${ }^{4}$ É nesse contexto que a teoria decolonial ganha terreno e se expande na América Latina.

Na perspectiva decolonial, a estrutura moderna de sistema de Estados na concepção vestfaliana foi construída a partir da colonialidade do poder, que se articula espacialmente em nível sistêmico. Os Estados-nações da América Latina seriam claros exemplos (Mignolo, 2017a, 2017b). A partir do século XV, foi imposta uma forma única de organizar politicamente a sociedade em terras que eram vistas como "em branco", reduzindo astecas, maias e incas à categoria "índios", e iorubás, zulus e tantos outros grupos se transformaram em "negros". A construção desses novos Estados em terras americanas seria uma expressão espacial do eurocentrismo e de uma clara divisão racial do trabalho.

Assim, a teoria decolonial rediscute o Estado-nação, não mais a partir da Teoria Geral dos Estados com base eurocêntrica, mas por meio da ideia de Estados plurinacionais. Importante ressaltar que isso não é a mesma coisa que dizer que existem várias nações dentro de um mesmo Estado, como a corrente multiculturalista revelou; mas, significa que não só as diferentes nações existem, como também é fundamental a necessidade de se pensar novos projetos de arranjos territoriais/políticos/éticos/epistêmicos para um mundo pluriversal e não mais universal (Chevallier, 2009). Assim:

3 Obviamente, esse é um resumo de tendências principais, e não a totalidade da produção geográfica. Historicamente, as obras de E. Reclus e P. Kropotkin são importantes exemplos de linhas teórico-conceituais que contestam o Estado-nação. Na geografia brasileira, é importante ressaltar obras de autores que se designam autonomistas, como M. Lopes de Souza, por exemplo.

4 Não cabe debater aqui essas importantes influências na Geografia Política mundial. Para tanto, ver, entre outros, Cooke e Rapino (2007) para a teoria queer e McDowell (1999) para a influência feminista. 
Fundamental ressaltar que o Estado-nação como órgão executor da soberania nacional e detentor do poder no contexto de monismo jurídico conduziu a sociedade plural a uma unidade, não necessariamente reconhecida por esta, autolegitimando o uso da força, o que incentiva o sociedade a se impor como "antipoder" para destituir o poder dominador, conforme expõe Dussel quando aborda as características da "hiperpotentia" (poder do povo): a vontade-de- vida, o consenso crítico e factibilidade da libertação (Gomes, E.; Lutz, 2019, p. 250).

Isso significa que a teoria decolonial não busca a supressão da organização social estatal. Trazer o debate decolonial significa compreender significativas mudanças político-jurídicas ocorridas nos últimos anos no mundo, especialmente na América Latina. $\bigcirc$ caso do Equador é um exemplo frisante (Walsh, 2014) ou ainda o debate sobre o que é "bem viver" em contraposição ao "american way of life" (Acosta, 2010). Para um exemplo brasileiro, Porto-Gonçalves e Quental (2012, p. 19) trazem as reservas extrativistas defendidas por Chico Mendes como uma amostra de que "começam a ganhar sentido ideias como pluralismo jurídico não mais recusando os direitos das gentes, o chamado direito consuetudinário, já não mais somente o direito hegemônico fundado nos princípios liberais do indivíduo e da propriedade privada".

No Brasil, apesar de escassa, já existem interessantes contribuições decoloniais na Geografia, como, por exemplo, o trabalho dos geógrafos anteriormente citados que versaram sobre as reservas extrativistas. Em 2017, fruto do seminário homônimo, de três antes, foi publicado o livro Geografia e giro descolonial, que reuniu um acúmulo desse debate por autores brasileiros, incluindo Porto-Gonçalves e também o texto já citado de Valter Cruz (2017). Com dezesseis capítulos que atravessam desde o debate teórico até temas mais empíricos - como os que discutem o movimento negro e as comunidades tradicionais -, essa contribuição recente revela o espírito de novidade que é ainda essa corrente para a geografia brasileira.

Assim, incorporar a agenda decolonial na Geografia Política brasileira é trazer a discussão sobre a formação do Estado-nação brasileiro e as visibilidades/invisibilidades oriundas desse processo. Significa pensar modos distintos de participação no Estado desses diferentes grupos, valorizando projetos político-territoriais alternativos. Toda uma nova engenharia político-geográfica (Azevedo, 2018) precisa ser discutida a partir da perspectiva decolonial. Como pensar e desenvolver uma estrutura político-administrativa e um sistema eleitoral que se baseiem na concepção de Estado plurinacional e não mais na concepção moderna de Estado-nação? Mais uma vez, vale lembrar que não se busca aqui negar a importância do Estado-nação e suas instituições para compreender o mundo social e garantir as chamadas "promessas da modernidade" (Castro, I., 2005, p. 39). Trata-se, na verdade, de questionar se essas promessas são as únicas possíveis e desejáveis, e como elas rebatem nos mais diferentes grupos no território.

\section{A perspectiva decolonial na Geografia Política em graduações do país}

Como exposto na introdução, o objetivo central deste artigo é avaliar se e em que medida se incorporou o debate decolonial ao ensino de Geografia Política em importantes universidades do país. Como defendemos, a decolonialidade enriquece o debate dentro do nosso campo, trazendo novas perspectivas, sem apagar as interpretações tradicionais. 
Para limitar o escopo da pesquisa, tomamos as universidades que têm nota 6 ou 7 na última avaliação quadrienal da Capes (2017). ${ }^{5}$ Apesar de se referirem mais diretamente aos programas de pós-graduação, essas notas também influenciam diretamente os cursos de graduação, por exemplo, com bolsas e na qualidade de laboratórios de pesquisa. Cabe ressaltar que esta pesquisa poderia ter usado o conceito preliminar de curso (CPC) divulgado pelo Instituto Nacional de Estudos e Pesquisas Educacionais (Inep) sobre os cursos de graduação, cujos dados seriam, a princípio, mais condizentes com os objetivos aqui propostos. Entretanto, essas notas se baseiam, em grande medida, no Exame Nacional de Desempenho dos Estudantes (Enade), que é constante alvo de críticas pelo boicote que sofre de muitos estudantes das universidades públicas e a pressão que exercem as universidades particulares para obter boas notas. ${ }^{6}$ Assim, ao optar pela última avaliação quadrienal da Capes 2017, buscamos a disciplina de Geografia Política de oito cursos de Geografia no Brasil - UFRJ e Unesp-PP (nota 7) e UFC, UFF, UFMG, Unicamp, UFPR e UFRGS (nota 6). Em geral, há nessas universidades importantes laboratórios de pesquisa em Geografia Política e professores com publicações relevantes no campo.

Para corroborar as informações trazidas sobre ementas e programas, também analisamos teses e dissertações defendidas sob orientação desses mesmos professores. Vale destacar que esse dado foge ao objetivo geral do artigo, pois o foco não são as pesquisas desenvolvidas, mas o maior momento no qual o aluno tem contato com os temas gerais da geografia: as aulas das disciplinas na graduação. Nem todos os alunos têm contato com os laboratórios de pesquisa e avançam para a pós-graduação, mas todos precisam cursar a disciplina no curso de bacharelado e/ou licenciatura - por isso, selecionamos apenas aqueles que têm Geografia Política como obrigatória. Ainda é importante sublinhar que apenas os professores responsáveis por essa disciplina foram analisados, o que não significa que outros pesquisadores desses departamentos a tenham discutido. Como o objetivo central deste artigo é analisar o que é ensinado ao aluno de graduação, limitamo-nos a esses professores.

Dois dos oito cursos analisados não têm a disciplina Geografia Política em sua grade curricular (Quadro 1), e chama atenção o fato de estarem entre os melhores cursos de Geografia do país (Unesp-PP e UFC), um deles com nota máxima (7). Sabemos que a construção de um currículo reflete características históricas e culturais em processos de (des)valorização de conhecimentos (Silva, 2003). Pesquisas futuras precisam revelar por quais razões ambas as universidades não incluíram Geografia Política no currículo base de suas graduações.

Buscou-se, assim, analisar os seis cursos restantes, suas ementas e programas disponíveis de algum ano recente. As ementas de todas as universidades estavam facilmente disponíveis, mas os programas de 2017 ora foram encontrados on-line, ora solicitados diretamente aos coordenadores do curso (não foi possível encontrar o programa do curso da Unicamp). Buscamos na ementa a presença da teoria decolonial, sabendo que é nela que estão os principais pontos do curso e que se baseia o professor para construir seu programa. Por fim, como já

5 No documento divulgado na página oficial da Capes, o curso de Geografia da Universidade de São Paulo (USP) obteve nota 5.

6 Reportagens desde 2010 apontam resultados inconclusivos do Enade, em função de boicotes deliberados (como o de 2010) ou da suspeita levantada pelo atual Ministro da Educação sobre o processo, sobretudo pela falta de uma punição real para os alunos com baixo rendimento nessa prova. Ver, por exemplo, Enade [...] (2010) e Moreno e Gravia (2019). 
dito anteriormente, optou-se por averiguar se nos programas havia autores hispânicos dentro da bibliografia obrigatória e complementar, como modo de valorizar a teoria decolonial debatida na América Latina e que seria o mais próximo de questões relevantes para o contexto brasileiro.

Destacamos que sabemos que existe uma prioridade na bibliografia obrigatória para textos em português, tendo em vista a dificuldade de alunos de graduação para acompanhar discussões em outros idiomas. Entretanto, na complementar, é muito comum a presença de textos em inglês ou francês, não justificando a partir da diferença linguística a falta de textos em espanhol (Quadro 1).

\section{Quadro 1 - Perspectiva decolonial na Geografia Política de graduações brasileiras}

\begin{tabular}{|l|c|c|c|}
\hline universidade & $\begin{array}{c}\text { Geografia Política } \\
\text { na grade curricular } \\
\text { obrigatória }\end{array}$ & $\begin{array}{c}\text { DECOLONIDADE } \\
\text { presente na ementa }\end{array}$ & $\begin{array}{c}\text { autores hispânicos na } \\
\text { bibliografia básica e } \\
\text { complementar }\end{array}$ \\
\hline UFRJ & $\operatorname{sim}$ & não & $6 \%$ \\
\hline Unesp-PP & não & - & - \\
\hline UFC & não & - & $5 \%$ \\
\hline UFF & $\operatorname{sim}$ & não & $5 \%$ \\
\hline UFMG & $\operatorname{sim}$ & não & S/I \\
\hline Unicamp & $\operatorname{sim}$ & não & $5 \%$ \\
\hline UFPR & $\operatorname{sim}$ & não & $8 \%$ \\
\hline UFRGS & $\operatorname{sim}$ & não & \\
\hline
\end{tabular}

fonte: Elaborado pelo autor.

A análise das ementas permite concluir que existem questões que são comuns em todos os cursos, como a discussão histórica da disciplina, a diferenciação entre Geografia Política e Geopolítica, a Geografia Eleitoral, a globalização e a análise do Estado moderno e suas políticas territoriais internas e externas. A teoria decolonial ou qualquer conceito utilizado em seu debate não foram encontrados em nenhuma ementa analisada.

Já quando tomamos os programas montados por seus professores a partir da ementa, é evidente a pouca atenção dada à literatura hispânica, decolonial ou não. A concentração absoluta é de texto em português (de autores brasileiros ou de traduções consagradas de autores estadunidenses ou europeus) na bibliografia obrigatória, sendo textos em francês e inglês os idiomas mais usados na complementar.

Para corroborar os dados apresentados anteriormente, optou-se também por analisar as últimas orientações de mestrado e doutorado dos professores responsáveis pela disciplina na graduação de Geografia Política. Cabe ressaltar que, apesar de não se referir diretamente aos cursos de bacharelado e/ou licenciatura, essa informação aponta as linhas de pesquisa desenvolvidas pelos professores e ajuda a entender esse afastamento nas ementas e programas.

A partir do currículo Lattes disponível on-line por todos os professores (em todos os casos os dados foram atualizados no ano de 2019), analisamos pelo título, palavras-chave e, caso houvesse alguma dúvida persistente, também pelo resumo, as dissertações e teses concluídas 
sob sua orientação. Como, até então, o professor da Universidade Federal de Minas Gerais não tinha dissertações ou teses concluídas, analisaram-se suas orientações de trabalhos de conclusão de curso. Categorizamos as pesquisas em cinco temas clássicos da Geografia Política que se ligam, a grosso modo, ao Estado e seus aparatos institucionais. A sexta categoria apontada foi aquela que identificamos como pesquisas que usam nova bagagem teórico-conceitual para analisar fenômenos que não se conectam, a princípio, com o Estado. Importa frisar que essas separações não podem ser vistas fora de seu objetivo analítico, isto é, as categorias criadas aqui não existem de modo tão estanque na realidade, pois muitas vezes dissertações e teses cortam diferentes temas da Geografia Política. Nesse sentido, teses e dissertações que não consideramos que façam parte do escopo da Geografia Política não entraram na contagem abaixo, como aquelas ligadas mais ao que se conhece como Geografia Urbana ou Geografia Econômica.

Quadro 2 - Tema das pesquisas sob orientação dos professores analisados
\begin{tabular}{|l|c|c|c|}
\hline tema da Geografia Política & $\begin{array}{c}\text { trabalho de } \\
\text { conclusão de curso }\end{array}$ & $\begin{array}{c}\text { número de } \\
\text { dissertações }\end{array}$ & $\begin{array}{c}\text { número de } \\
\text { teses }\end{array}$ \\
\hline políticas públicas & 2 & 13 & 4 \\
\hline $\begin{array}{l}\text { estrutura político-administrativa } \\
\text { brasileira }\end{array}$ & 2 & 9 & 4 \\
\hline $\begin{array}{l}\text { Geopolítica - limites e fronteiras } \\
\text { na globalização }\end{array}$ & 0 & 9 & 4 \\
\hline nacionalismo e regionalismo & 0 & 1 & 0 \\
\hline $\begin{array}{l}\text { sistema político democrático- } \\
\text { relação entre instituinte e } \\
\text { instituído }\end{array}$ & 0 & 3 & 0 \\
\hline $\begin{array}{l}\text { Geografia Política para além } \\
\text { da figura do Estado e suas } \\
\text { instituições }\end{array}$ & 0 & 4 & 0 \\
\hline
\end{tabular}

fonte: Elaborado pelo autor.

Destacam-se algumas características marcantes das pesquisas desenvolvidas sob orientação dos professores responsáveis pela disciplina de Geografia Política nessas graduações. Primeiro, a óbvia proximidade entre os trabalhos desenvolvidos pelo mestrando e/ou doutorando com as linhas de pesquisa de cada momento da vida acadêmica do professor. Nesse sentido, na UFRJ, por exemplo, há atualmente uma abundância de discussões a respeito de patrimônio como política pública ${ }^{7}$ ou, no caso da Unicamp, trabalhos na área de divisão territorial e nos últimos anos sobre a ideia de território usado e política pública. Em segundo lugar, temas ligados à geopolítica estão predominantemente sendo realizados com o professor da Universidade Federal do Rio Grande do Sul, talvez devido a uma importância maior do tema para um estado fronteiriço que é diretamente afetado por questões como o Mercosul e conflitos de fronteira.

7 A Geografia Política da Universidade Federal do Rio de Janeiro vem perdendo autores consagrados na área, seja por aposentadoria ou por morte prematura. É reconhecido o papel de Iná Elias de Castro, Lia Osório Machado e Bertha Becker no desenvolvimento da área. Antes com três professores da área, hoje o departamento da UFRJ conta apenas com o professor Rafael Winter Ribeiro, especialista em patrimônio. 
Por último, chamou atenção para o número muito recente de trabalhos que não lidam diretamente com o Estado ou com suas instituições. Em duas dissertações na Universidade Federal Fluminense, foram investigadas a geografia política das manifestações, com ênfase nas estratégias do movimento Black Bloc, e também a construção da sociabilidade política no espaço público de um parque no Rio de Janeiro. Já na Universidade Federal do Paraná, a geografia política dos movimentos populares - camponeses e urbanos - foi o tema desenvolvido por dois mestrandos. Se, por um lado, essas dissertações já apontam um caminho novo a ser trilhado pela Geografia Política brasileira, por outro, mais uma vez, a discussão decolonial não aparece como relevante nas produções da pós-graduação desses professores que lidam com a disciplina na graduação.

Em suma, mesmo sendo considerado por diferentes autores das ciências humanas latino-americanas e especialmente pela Geografia discutida em outras partes do mundo uma ruptura e um aporte teórico-metodológico importante do final do século XX e início do século XXI, é evidente que a Geografia Política brasileira ensinada nas graduações das principais universidades do país ainda não considera o debate decolonial relevante. Por quê?

\section{Por que a ausência do debate decolonial na Geografia Política brasileira na graduação? Algumas reflexões}

No tópico anterior, restou evidente a falta das discussões decoloniais nos currículos da Geografia Política das principais graduações do Brasil, cujas análises têm como elementos centrais o Estado-nação e diferentes ramificações. ${ }^{8}$ Colin Flint e Peter Taylor (2011[1989]) já afirmavam que esse foco no Estado havia tornado a Geografia Política um campo conservador dentro da ciência geográfica ou, ainda, o próprio Claude Raffestin (1993) já havia apontado o caráter "estadocêntrico" da disciplina. Para os autores americanos e também corroborado por Mary Gilmartin (2009), os geógrafos políticos estavam tão preocupados em privilegiar o Estado como entidade político-social, que acabaram falhando em investigá-lo como uma arena de contestação entre, por exemplo, os diferentes grupos que vivem nele. Entretanto, Gilmartin afirmava já em 2009 que esse cenário estaria mudando, a partir da incorporação dos debates feministas, da teoria queer e daqueles que discutiam os processos de patrimonialização a partir de grupos marginalizados. A perspectiva decolonial, entretanto, ficou fora de sua análise.

$\bigcirc$ texto de Gilmartin (2009) faz parte da coletânea Key Concepts in Political Geography, para a qual importantes autores foram selecionados para escrever uma breve discussão sobre os principais conceitos da Geografia Política. Sendo um livro de alto apelo, chama atenção a decolonialidade não estar presente entre os 28 conceitos escolhidos. Quanto à Geografia Política nas graduações brasileiras, defendemos que há três possíveis explicações que não se excluem, mas juntas podem dar pistas que ajudam a compreender essa lacuna existente no ensino de Geografia Política desses centros universitários. Longe de esgotar as possibilidades de explicação, as três seguintes razões são aquelas que acreditamos serem as mais evidentes.

8 Cumpre destacar que a perspectiva decolonial tem rebatimentos em outras áreas da Geografia, como aqueles apresentados por Name (2016), e a construção de uma agenda de pesquisa decolonial na análise de imagens. Entretanto, repetimos, nosso foco é a Geografia Política em cursos de graduação. 
Em primeiro lugar, é notório um afastamento da Geografia Política brasileira dos trabaIhos realizados na América Latina, região que concentra a maior produção acadêmica sobre a perspectiva decolonial, especialmente aquela que discute, como já dito anteriormente, o giro decolonial. Em contrapartida, é conhecida a influência histórica da geografia europeia, especialmente a francesa, na produção geográfica brasileira (Andrade, 1991, 1999; Gomes, P., 1996; Carlos, 2002). Entretanto, além de ser apenas uma marca do passado, até hoje as referências bibliográficas dos trabalhos em Geografia Política tendem a se limitar a autores brasileiros, americanos e europeus. Trabalhos de origem hispânica raramente são usados ou citados, ilustrando o que se chama, na teoria decolonial, geopolítica do conhecimento (Ramírez, 2011; Mignolo, 2014a).

Essa afirmação é corroborada pela análise da bibliografia dos cursos de Geografia Política citados no segundo tópico. Como já exposto, há uma concentração absoluta de literatura em português, inglês e francês, relegando a segundo plano os estudos realizados em espanhol. Sem dúvida, a maior proximidade entre as línguas latinas torna improvável a explicação baseada na dificuldade de compreensão do idioma. Soma-se a isso um dado que impressiona: cinco dos seis professores responsáveis por ministrar aulas de Geografia Política (UFRJ, UFF, UFRGS, UFMG e Unicamp) fizeram parte de sua formação (doutorado completo, período sanduíche ou pós-doutorado) fora do Brasil, todos em instituições francesas.?

As duas outras possíveis razões que explicam o afastamento da Geografia Política ensinada nas graduações da perspectiva decolonial residem, acreditamos, na própria agenda promovida por essa corrente epistemológica. Como apresentado no primeiro tópico, o objetivo central dos autores decoloniais é desconstruir noções que se pretendem únicas e universais, como os casos que Walsh (2014) designa como liberal-economicista imperial e marxismo revolucionário. Apesar de aparentemente opostos, Quijano (1992), Mignolo (2014a), Walsh (2014) e Linera (2014) concordam que ambos são produtos da modernidade e, apesar de ter conteúdos invertidos, não divergem na lógica ou na forma. Defendemos que essas duas correntes são aquelas que mais influenciam a produção da Geografia Política brasileira.

A tradição estatal e a defesa pela democracia representativa é, claramente, a base teórico-conceitual que sustenta um dos principais subcampos da Geografia Política: os estudos sobre a espacialidade do voto. A Geografia Eleitoral esteve na construção da ciência geográfica com o trabalho de André Sigfrield (1913), passou pela Geografia Teorético-quantitativa e retomou com força nas últimas décadas a partir de novas bases teórico-conceituais e uso de metodologias quantitativas (Voda et al., 2017; Evans et al., 2017; Lappie; Marschall, 2018). De qualquer modo, o que se destaca é que, em geral, a Geografia Eleitoral parte do pressuposto que o Estadonação é uma entidade político-territorial legítima, assim como a democracia representativa e seus métodos.

Por outro lado, autores e pesquisas de base marxista ou pós-estruturalista tendem a ver com maus olhos os estudos produzidos pela Geografia Eleitoral. $\bigcirc$ caso da obra de Colin Flint e Peter Taylor (2011[1989]) é evidente. Para os autores, a Geografia Eleitoral serve como uma "geografia do suporte" para a democracia elitista liberal e afasta o geógrafo da crítica ao sistema-mundo

9 Esses dados foram recolhidos da plataforma Lattes de cada professor responsável nas instituições pela disciplina de Geografia Política. Apenas o professor da UFPR não tinha em seu currículo instância de doutorado ou pós-doutorado fora do país. Novamente, UFC e Unesp-PP não têm Geografia Política como disciplina obrigatória. 
capitalista, isto é, preocupar-se com a espacialidade do voto seria um modo de legitimar a "escala da ideologia" do Estado-nação. Em suma, para os autores, buscar a democracia real em países periféricos não teria sentido, já que a estrutura capitalista de sistema-mundo impediria o seu florescimento. Sabendo da importância da crítica de cunho estruturalista na Geografia brasileira, é evidente que essas considerações afetaram as pesquisas realizadas no Brasil.

Além da espacialidade do voto, destacam-se também os estudos sobre políticas públicas espaciais. De modo geral, há diferentes pesquisas que se preocupam em analisar o modo pelo qual as políticas públicas promovem transformações no território e outras que "criticam incisivamente o Estado enquanto representante de segmentos poderosos e de interesses escusos" (Mello-Théry, 2011, p. 15). Como já afirmado anteriormente, apesar de buscarem inverter os conteúdos, o importante aqui é destacar a centralidade do Estado-nação como foco de análise. Vale a pena sublinhar o número de dissertações e teses orientadas dentro desse tema (Quadro 2).

Num artigo que buscou pontes entre políticas públicas e Geografia Política, Rodrigues (2014, p. 153) afirmou que "mais especificamente, o campo da geografia política (e da geopolítica), classicamente se interessaram pelos efeitos territoriais dos conflitos, sobretudo dos conflitos interestatais". Apesar de a autora apontar a necessidade de expandir essa ideia, os conceitos usados para isso ("governança territorial", "participação" e "políticas públicas territoriais") trazem novos atores políticos (principalmente da sociedade civil) à estrutura de participação e representação definidos pelo Estado.

Em tese de doutorado defendida no departamento de Geografia da Universidade de São Paulo, Eduardo Karol (2014) teceu duras críticas a grande parte dos autores históricos e atuais da Geografia Política brasileira. Apesar de não concordarmos com o teor de algumas delas, ${ }^{10}$ o autor afirmou que ainda não se havia construído na Geografia Política brasileira a prática da "tradução de diversas obras que amplie a formação dos estudantes com análises de gênero, como as Geopolíticas femininas" (Karol, 2014, p. 98), tornando-se um subcampo ainda atrelado à figura do Estado e seus aparatos.

Diferentemente de Karol (2014), não se afirma aqui que, ao discutir política pública, o geógrafo político se tenha transformado num mero agente "subserviente às necessidades do Estado corporativo" (Harvey, 2017[1974]), já que muitas dessas pesquisas interpretam as políticas públicas a partir de uma visão mais crítica do Estado. Em seu artigo, Mello-Théry (2011, p. 12) afirma que "o pensamento teórico da Geografia nas políticas públicas concentra-se em uma grande linha teórica, crítica, de base marxista e/ou estruturalista". Ainda assim, o geógrafo analisa as políticas públicas como sendo as "decisões e ações revestidas da autoridade soberana do poder público" (Mello-Théry, 2011, p. 12).

Assim, as investigações produzidas por essas matrizes teórico-conceituais aparentemente opostas serviriam, acreditamos, para afastar a Geografia Política da teoria decolonial. Apesar de concordar com grande parte das considerações que teceram os geógrafos críticos ao Estado-nação e ao sistema capitalista, a decolonialidade defende que o marxismo-revolucionário não se configura como uma "epistemologia do sul" por ser parte também do pensamento moderno (Dantas, 2015).

10 Destacam-se aqui as simplificações que o autor faz da obra de Bertha Becker, ao afirmar, por exemplo, que ela teria procurado manter a Geografia brasileira colonizada (Karol, 2014, p. 161), e da discussão de Iná Elias de Castro, inclusive com dados equivocados sobre suas orientações de mestrado e doutorado ao longo da década de 1990. 
Talvez por essas razões geógrafos brasileiros que usam a teoria decolonial em suas análises se afastem da denominação Geografia Política e geralmente designem seus trabalhos como da Geografia Social." Assim, percebe-se que nos cursos de graduação avaliados, a Geografia Política como disciplina se tornou um campo de estudo concentrado majoritariamente ao redor das questões estatais, enquanto outros temas também relevantes ficaram sob o guarda-chuva de distintos subcampos.

\section{Considerações finais}

Este artigo pretendeu revelar como a teoria decolonial está ou não presente no que se denomina Geografia Política nos cursos de graduação de universidades brasileiras. Vale destacar que trazer a perspectiva decolonial não significa renunciar à análise dos aparatos estatais, de suas estratégias eleitorais ou das políticas públicas espaciais. Essas são agendas importantes, e negá-las seria uma perda. Por outro lado, ao pensar num paradigma-outro, que questiona a própria ideia de Estado-nação e seus derivados, enriquece e torna mais complexas as análises empreendidas por geógrafos políticos.

Acreditamos que a decolonialidade pode ajudar a Geografia Política brasileira de três modos: primeiro, para finalmente olhar para a América Latina e a língua espanhola como fontes de conhecimento acadêmico, incorporando seus debates e interpretações. Segundo, para suspeitar de ideias universais e únicas de mundo, como a teoria "marxista-revolucionária" e a "liberal-imperialista", para usar expressões caras à literatura decolonial. E, por último, trazendo uma nova perspectiva sobre o Estado-nação e sua ordem global, colocando a ideia de Estado pluricultural no centro do debate. Busca-se, assim, enriquecer o próprio campo da Geografia Política, trazendo discussões profícuas em países tão próximos, mas ainda academicamente distantes.

Aqui, procuramos sinalizar novos horizontes, cujo projeto é romper com o modelo epistemológico eurocêntrico, e defendemos que se os incorpore ao subcampo da Geografia Política, fenômeno que se atrasa no Brasil pela insistência de geógrafos a não ver como interessantes fenômenos políticos fora do Estado-nação e de seus aparatos nas mais diferentes escalas. Assim, uma contribuição geográfica menos colonial, mais original e que tenha como incumbência principal desconstruir chaves interpretativas tradicionalmente definidas pode enriquecer ainda mais esse campo da Geografia.

\section{Referências}

ABDALLA, M. M.; FARIA, A. Em defesa da opção decolonial em administração: rumo a uma concepção de agenda. In: COLÓQUIO INTERNACIONAL DE EPISTEMOLOGIA E SOCIOLOGIA DA CIÊNCIA DA ADMINISTRAÇÃO, 5., 2015, Florianópolis. Anais... Florianópolis, mar. 2015.

ACOSTA, A. El buen vivir en el camino del post-desarrollo: una lectura desde la Constitución de Montecristi. Quito: FES-Ildis, 2010.

11 Ver, por exemplo, as obras do geógrafo Carlos Walter Porto-Gonçalves (2010) e seus trabalhos sobre os movimentos sociais agrários. O próprio autor em seu currículo Lattes afirma que suas pesquisas estão na área de Geografia Social, evitando usar a expressão Geografia Política. 
ANDRADE, M. C. A construção da geografia brasileira. Revista Finisterra, v. 34, n. 67, p. 21-30, 1999.

ANDRADE, M. C. A AGB e o pensamento geográfico no Brasil. Revista Terra Livre, n. 9, p. 143-154, 1991.

AZEVEDO, D. A. Os limites da democracia participativa: uma análise a partir dos Conselhos Municipais no Rio de Janeiro. GEOgraphia, v. 20, n. 43, p. 54-70, 2018.

BALLESTRIN, L. América Latina e o giro decolonial. Revista Brasileira de Ciência Política, Brasilia, n. 11, p. 89-117, 2013.

CAPES. COORDENAÇÃO DE APERFEIÇOAMENTO DE PESSOAL DE NÍVEL SUPERIOR. Relatório da Avaliação Quadrienal 2017: Geografia. Brasilia, DF: Ministério da Educação, 2017. Disponível em: http://www.capes.gov.br/images/stories/ download/avaliacao/relatorios-finais-quadrienal-2017/20122017-Comunicacao-quadrienal.pdf. Acesso em: 1 jun. 2019.

CARLOS, A. F. A. A geografia brasileira, hoje: algumas reflexões. Revista Terra Livre, n. 18, p. 161-178, 2002.

CASTRO, E. V. Metafísicas canibais: elementos para uma antropologia pós-estrutural. São Paulo: Cosac \& Naify, 2015.

CASTRO, E. V. O nativo relativo. Mana, v. 8, n. 1, p. 15-45, abr. 2002.

CASTRO, I. E. Escala e pesquisa na geografia. Problema ou solução? Espaço Aberto, Rio de Janeiro: UFRJ, v. 4, n. 1, p. 87-100, 2014.

CASTRO, I. E. Geografia e política. Rio de Janeiro: Bertrand Brasil, 2005.

CHEVALLIER, J. O Estado pós-moderno. 3a ed. Belo Horizonte: Fórum, 2009.

COOKE, T.; RAPINO, M. The migration of partnered gays and lesbians between 1995 and 2000. Professional Geographer, v. 59, n. 3, p. 285-297, 2007.

CORREAA, R. L. Espaço: um conceito-chave da geografia. In: CASTRO, I. E.; GOMES, P. C. C.; CORREAA, R. L. (Org.). Geografia: conceitos e temas. Rio de Janeiro: Bertrand Brasil, 1996. p. 14-42.

COSTA, W. M. Geografia política e geopolítica. São Paulo: Edusp, 2010.

CRUZ, V. C. Geografia e pensamento descolonial: notas sobre um diálogo necessário para a renovação do pensamento crítico. In: CRUZ, V. C.; OLIVEIRA, D. A. (Org.). Geografia e giro descolonial: experiências, ideias e horizontes de renovação do pensamento crítico. Rio de Janeiro: Letra Capital, 2017. p. 15-36.

CRUZ, V. C.; OLIVEIRA, D. A. (Org.). Geografia e giro descolonial: experiências, ideias e horizontes de renovação do pensamento crítico. Rio de Janeiro: Letra Capital, 2017.

DANTAS, L. T. F. Descolonização epistêmica: a geografia política das filosofias. Rebela, v. 5, n. 3, p. 10-27, set./dez. 2015. 
ENADE tem boicote de alunos de universidades federais. Veja, 22 nov. 2010. Disponível em: https://veja.abril.com.br/educacao/enade-tem-boicote-de-alunos-de-universidades-federais/. Acesso em: 7 out. 2019.

ESCOBAR, A. Mundos y conocimientos de otro modo: el programa de investigación de modernidad/colonialidad latinoamericano. Tabula Rasa, Bogotá: UCMC, p. 51-86, 2003.

EVANS, J.; ARZHEIMER, K.; CAMPBELL, R.; COWLEY, P. Candidate localness and voter choice in the 2015 General Election in England. Political Geography, n. 59, p. 61-71, 2017.

FLINT, C.; TAYLOR, P. Political geography: world-economy, nation-state and locality. London: Prentice Hall, 2011[1989].

GILMARTIN, M. Nation-state. In: GALLAHER, C.; DAHLMAN, C. T.; GILMARTIN, M.; MOUNTZ, A. Key Concepts in Political Geography. Washington DC: Sage, 2009. p. 19-27.

GOMES, E. B.; LUTZ, M. L. S. Estado-nação e democracia em uma perspectiva decolonial: uma análise a partir da perspectiva boliviana. Revista Argumentum, v. 20, n. 1, p. 249-272, jan./abr. 2019.

GOMES, P. C. C. Geografia e modernidade. Rio de Janeiro: Bertrand Brasil, 1996.

GROSFOGUEL, R. A estrutura do conhecimento nas universidades ocidentalizadas: racismo/ sexismo epistêmico e os quatro genocídios/epistemicídios do longo século XVI. Sociedade e Estado, v. 31, n. 1, p. 25-49, 2016.

GUHA, R. Dominance without hegemony: history and power in colonial India. Harvard: Harvard University Press, 1998.

HARVEY, D. Que tipo de geografia para que tipo de política pública? Boletim Campineiro de Geografia, v. 7, n. 2, 2017[1974].

HARVEY, D. Condição pós-moderna. São Paulo: Edições Loyola, 1993.

KAROL, E. Geografia política e geopolítica no Brasil (1982-2012). Tese (Doutorado em Geografia Humana) - Faculdade de Filosofia, Letras e Ciências Humanas, Universidade de São Paulo, São Paulo, 2014.

LAPPIE, J.; MARSCHALL, M. Place and participation in local elections. Political Geography, v. 64, p. 33-42, 2018.

LINERA, A. G. Democracia liberal vs. democracia comunitaria. In: LINERA, A. G.; MIGNOLO, W., WALSH, C. Interculturalidad, descolonización del Estado y del conocimiento. Ciudad Autónoma de Buenos Aires: Del Signo, 2014. p. 51-58.

LOBACK, V.; BEZERRA, A. C. A formação territorial do Brasil nos livros didáticos de geografia: em busca de uma análise descolonial. Geografares, n. 27, p. 103-220, out./dez. 2018. 
MALDONADO-TORRES, N. Sobre la colonialidad del ser: contribuciones al desarrollo de un concepto. In: CASTRO-GÓMEZ, S.; GROSFOGUEL, R. (Org.). E1 giro decolonial: reflexiones para una diversidad epistémica más allá del capitalismo global. Bogotá: Siglo del Hombre, 2007. p. 127-167.

MCDOWELL, L. Gender, identity and place: understanding feminist geographies. Minneapolis: University of Minnesota Press, 1999.

MELLO-THÉRY, N. A. Política (e ação) pública, território e o papel da geografia. Revista da Anpege, v. 7, n.1, p. 11-19, out. 2011.

MIGNOLO, W. Colonialidade: o lado mais escuro da modernidade. Revista Brasileira de Ciências Sociais, v. 32, n. 94, jun. 2017a.

MIGNOLO, W. Desafios decoloniais hoje. Epistemologias do Sul, Foz do Iguaçu, n. 1, v. 1, p. 12-32, $2017 b$.

MIGNOLO, W. (Org.). Capitalismo y geopolítica del conocimiento. Ciudad Autónoma de Buenos Aires: Del Signo, 2014a.

MIGNOLO, W. Desobediencia epistémica: retórica de la modernidad, lógica de la colonialidad y gramática de la descolonidad. Ciudad Autónoma de Buenos Aires: Del Signo, 2014b.

MIGNOLO, W. El pensamiento des-colonial, desprendimiento y apertura: un manifiesto. In: LINERA, A. G.; MIGNOLO, W., WALSH, C. Interculturalidad, descolonización del Estado y del conocimiento. Ciudad Autónoma de Buenos Aires: Del Signo, 2014c. p. 59-88.

MORENO, A. C.; GRAVIA, G. 3,3\% dos cursos de faculdades privadas tiveram conceito máximo no Enade 2018. G1, 4 out. 2019. Disponível em: https://veja.abril.com.br/educacao/enade-tem-boicote-de-alunos-de-universidades-federais/ Acessado dia 07/10/2019 e https://gl.globo.com/educacao/noticia/2019/10/04/33percent-dos-cursos-de-faculdades-privadas-tiveram-conceito-maximo-no-enade-2018.ghtml. Acesso em: 7 out. 2019.

NAME, L. Geografias e imagens: notas decoloniais para uma agenda de pesquisa. Espaço e Cultura, Rio de Janeiro: UERJ, v. 39, p. 59-80, 2016.

OLIVEIRA, M. G. Os sons do silêncio: interpelações feministas decoloniais à história da historiografia. História da Historiografia, v. 11, n. 28, p. 104-140, set./dez. 2018.

PORTO-GONÇALVES, C. W. Décoloniser: l'esprit de Cochabamba. Projet, v. 318, p. 52-59, 2010 .

PORTO-GONÇALVES, C. W.; QUENTAL, P. A. Colonialidade do poder e os desafios da integração regional na América Latina. Polis, n. 31, p. 1-34, 2012.

QUIJANO, A. Colonialidade do poder, eurocentrismo e América Latina. In: A colonialidade do saber: eurocentrismo e ciências sociais. Perspectivas latino-americanas. Buenos Aires: Clacso, 2005. p. 116-142 
QUIJANO, A. Colonialidad del poder y clasificación social. Journal of World-Systems, v. 11, n. 2, p. 342-86, 2000.

QUIJANO, A. Colonialidad y modernidad/racionalidad. Perú Indígena, Lima, v. 12, n. 29 , p. 11-20, 1992.

RAFFESTIN, C. Por uma geografia do poder. São Paulo: Ática, 1993.

RAMÍREZ, M. Y. Geopolítica del conocimiento en América Latina: la construcción de espacios históricos otros. Revista Austral de Ciencias Sociales, n. 21, p. 111-136, 2011.

ROCHA, P. D. O determinismo racial e geográfico no discurso geopolítico moderno/colonial: por uma geopolítica decolonial. Conjuntura Global, v. 7, n. 3, p. 243-259, 2018.

RODRIGUES, J. N. Políticas públicas e geografia: retomada de um debate. Geousp - Espaço e Tempo (Online), São Paulo, v. 18, n. 1, p. 152-164, 2014.

RUBBO, D. A. Anibal Quijano e a racionalidade alternativa na América Latina: diálogos com Mariátegui. Estudos Avançados, n. 32, v. 94, p. 391-405, 2018.

SANTOS, B. S. Gramática do tempo: por uma nova cultura política. São Paulo: Cortez, 2006.

SAUERBRONN, F. F; AYRES, R. M.; LOURENÇO, R. L. Perspectivas pós-coloniais e decoloniais: uma proposta de agenda de pesquisa em contabilidade no Brasil. Custos e Agronegócio, v.13, n. 3, p. 120-148, jul./set. 2017.

SEGATO, R. L. La perspectiva de colonialidad del poder. In: PALERMO, Z.; QUIN-TERO, P. (Org.). Anibal Quijano: textos de fundación. Buenos Aires: Del Signo, 2014. p. 9-39.

SIGFRIELD, A. Tableau politique de la France de l'Ouest sous la Troisième République. Paris: A. Colin, 1913.

SILVA, T. T. Documentos de identidade: uma introdução às teorias do currículo. $2 \mathrm{a}$ ed. Belo Horizonte: Autêntica, 2003.

VODA, P.; SVACINOVÁ, P.; SMOLKOVÁ, A.; BALÍK, S. Local and more local: impact of size and organization type of settlements units on candidacy. Political Geography, n. 59, p. 24-35, 2017.

WALSH, C. Interculturalidad y colonialidad del poder. Un pensamiento y posicionamiento otro desde la diferencia colonial. In: LINERA, A. G.; MIGNOLO, W.; WALSH, C. Interculturalidad, descolonización del Estado y del conocimiento. Ciudad Autónoma de Buenos Aires: Del Signo, 2014. p.17-50. 